Cunningham, D. J. C., and Lloyd, B. B., (1963). The Regulation of Human Respiration. J. S. Haldane Centenary Symposium, Oxford. Shaw, D. G., Lahiri, S., and Lloyd, B. B. (1961). Quart. F. exp. Physiol., 46, 323.

Davenport, A., and Paton, W. D. M. (1962). Brit. F. industr. Med., 19, 19.

Dejours, P. (1959). F. Physiol. (Paris), 51, 163.

Donald, K. W. (1959). Progr. cardiovasc. Dis., 1, 298.

Dornhorst, A. C. (1963). Brit. med. Bull., 19, 4.

DuBois, A. B., Botelho, S. Y., and Comroe, J. H., jun. (1956). F. clin. Invest., 35, 327.

Finley, T. N., Swenson, E. W., and Comroe, J. H., jun. (1962). Ibid., 41,

Halmagyi, D. F. J., and Colebatch, H. J. H. (1961). Ibid., 40, 1785.

Hammond, J. D. S. (1957). Clin. Sci., 16, 481.

(1961). Ibid., 20, 107

Hanley, T., Platts, M. M., Clifton, M., and Morris, T. L. (1958). Quart. 7. $M e d ., 27,155$.

Hughes, R., May, A. J., and Widdicombe, J. G. (1958). F. Physiol. (Lond.), 142, 306
McDermott, M., Collins, M. M., and Fletcher, C. M. (1964). In press. McIlroy, M. B. (1959) Progr. cardiovasc. Dis., 1, 284.

Matell, G. (1963). Acta physiol. scand., 58, Suppl. No. 206.

Nahas, G. G., and Fink, B. R. (1963). Ann. N.Y. Acad. Sci., 109, 411

Nielsen 1 ., and Smith, H. (1951). Acta physiol. scand., 24, 293.

Orie, N. G. M., and Sluiter, H. J. (1961). Bronchitis : An International rie, N. G. M., and Sluiter, H. J. (1961). Bronchitis : An International
Symposium. Royal VanGorcum Ltd., Netherlands. C. C. Thomas, Springfield.

Penman, R. W. B. (1962a). Clin. Sci., 22, 155.

(1962b). Ibid., 23, 5

de Reuck, A. V. S., and O'Connor, M. (1962). Ciba Foundation Symposium on Pulmonary Structure and Function. Churchill, London.

Richards, D. W., jun. (1953). Circulation, 7, 15.

Saxton, G. A. jun., Rabinowitz, M., Dexter, L., and Haynes, F. (1956) 7. clin. Invest., 35, 611 .

Sproule, B. J., Mitchell, J. H., and Miller, W. F. (1960). Ibid., 39, 378. Stein, M., Kimbel, P., and Johnson, R. L., jun. (1961). Ibid., 40, 348 .

White, H. C., Butler, J., and Donald, K. W. (1958). Clin. Sci., 17, 667.

Whitaker, W. (1954). Quart. F. Med., 23, 57

\title{
Systemic Embolism and Anticoagulant Prophylaxis in Rheumatic Heart Disease
}

\author{
PAUL SZEKELY,* M.D.
}

It has been estimated that a history of systemic embolism is likely to be obtained in 9 to $14 \%$ of patients suffering from rheumatic heart disease, and that the embolism is cerebral in about $60 \%$, peripheral in $30 \%$, and visceral in $10 \%$ of the cases (Wood, 1954, 1956). As arterial embolism can be a serious complication of rheumatic heart disease and can occur occasionally in patients who have little or no cardiac disability, the long-term management of rheumatic heart disease must take into account the risks of initial and recurrent embolism. In the present study an attempt is made to assess this risk over a longer period in medically and surgically treated cases of rheumatic heart disease and to examine the present position of anticoagulant prophylaxis.

\section{Material}

A total of 1,017 patients with acute rheumatic fever with or without cardiac involvement or with chronic rheumatic heart disease have been personally studied between 1942 and 1962. Patients with a history of acute rheumatic manifestations who at the time of writing had no conclusive evidence of valvular lesion, and those with established valvular disease followed for less than one year, have not been considered for the present analysis. Thus 754 patients (656 females, 98 males) with established rheumatic cardiovalvular disease followed for a total period of 5,833 patient-years form the basis of the present observations. The ages of the patients when first seen ranged from 8 to 73 years. The predominant valvular lesion was mitral stenosis in $90 \%$, mitral incompetence in $6.5 \%$, aortic incompetence in $2.5 \%$, and aortic stenosis in $1 \%$ of the cases.

All embolic episodes included in this analysis occurred during the said period of observation. So far as one could ascertain from the history, only four embolic episodes occurred prior to our first examination of the patients. Emboli found at post-mortem examination only and not diagnosed clinic- ally were also excluded from the analysis, and so were emboli occurring in the presence of bacterial endocarditis.

\section{Clinical Observation}

Systemic embolism occurred in 72 patients; 14 of them had more than one embolus ; the total number of embolic episodes amounted to 89 . The incidence and site of emboli in relation to the cardiac rhythm are summarized in Table $I$.

TABLB I.-Systemic Embolism in Rheumatic Heart Disease. Incidence and Site of Emboli in Relation to Cardiac Rhythm

\begin{tabular}{|c|c|c|c|c|c|c|c|c|}
\hline \multirow[b]{2}{*}{ Cardiac Rhythm } & \multirow[b]{2}{*}{ 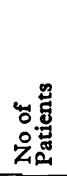 } & \multirow{2}{*}{ 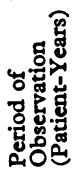 } & \multicolumn{6}{|c|}{ Embolic Group } \\
\hline & & & 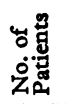 & 息 & 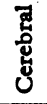 & 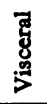 & 递 & बूँ \\
\hline $\begin{array}{l}\text { Sinus } \\
\text { Atrial fibriliation }\end{array}$ & $\begin{array}{l}663 \\
219\end{array}$ & $\begin{array}{l}4,749 \\
1,084\end{array}$ & $\begin{array}{l}25 \\
49\end{array}$ & $\begin{array}{r}4 \\
17\end{array}$ & $\begin{array}{l}27 \\
36\end{array}$ & $\frac{1}{3}$ & $\begin{array}{l}0 \\
1\end{array}$ & $\begin{array}{l}32 \\
57\end{array}$ \\
\hline Total $\quad$. & 754* & 5,833 & $72 \dagger$ & 21 & 63 & 4 & 1 & 89 \\
\hline
\end{tabular}

+2 patients included in both groups.

In the embolic group there were 57 females and 15 males. The ages of the patients at the time of the first embolic episode ranged from 17 to 63 years (see Chart). The highest incidence was encountered in the fifth decade.

All patients in the embolic group had mitral-valve disease, pure or predominant mitral stenosis being present in 65 patients, and predominant mitral incompetence in 7. Haemodynamically significant aortic incompetence was present in three patients and aortic stenosis in one patient. Two patients had significant tricuspid stenosis as well. All patients had moderate to great cardiac enlargement (cardiothoracic ratio $>55 \%$ ).

There were 17 embolic recurrences in 14 patients during a period of 214 patient-years. Of the recurrences, $40 \%$ occurred within one month and $66 \%$ within 12 months of the 
initial embolus. Seven recurrences occurred in sinus rhythm in five patients during a follow-up period of 66 patient-years, and 10 recurrences in atrial fibrillation in nine patients during a follow-up period of 148 patient-years.

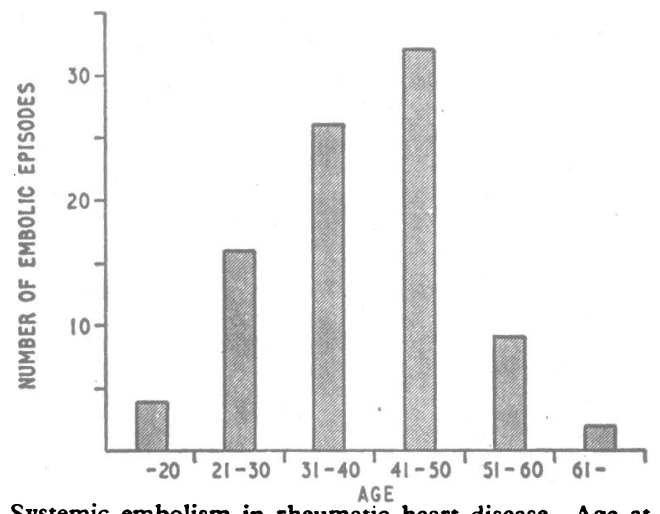

Systemic embolism in rheumatic heart disease. Age at time of embolism.

\section{Atrial Fibrillation}

Fifty-seven embolic episodes occurred in atrial fibrillation. Of these, 37 occurred in patients who had been under observation before the onset of atrial fibrillation and in whom it was possible to ascertain the time of onset of atrial fibrillation with reasonable accuracy. In this latter group of patients just over a third of the emboli occurred within four weeks, and nearly two-thirds within 12 months of the onset of fibrillation. The relevant data are summarized in Table II.

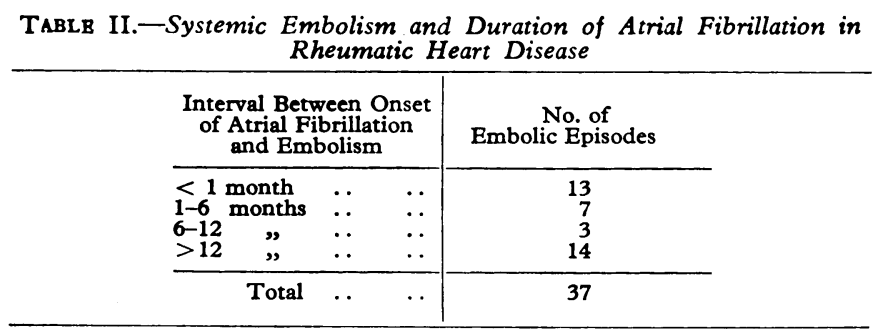

\section{Mitral Valvotomy}

In this series 168 patients have undergone mitral valvotomy. The post-operative follow-up of 156 survivors covers 806 patient-years. During this period 27 embolic episodes occurred in 22 patients. The time interval between valvotomy and embolization is shown in Table III. Six of the embolic episodes occurred at operation or within 24 hours after it. Three of the patients also had one embolic episode one year, one year, and three years, respectively, before mitral valvotomy. Only two of the embolic episodes in this group occurred during anticoagulant treatment.

In the group of patients who have undergone mitral valvotomy there were 11 who had embolic episodes preoperatively and none post-operatively. One of these patients died in the immediate post-operative period; the remaining

TABLE III.-Systemic Embolism After Mitral Valvotomy (168

\begin{tabular}{|c|c|c|c|c|c|c|c|}
\hline \multirow{2}{*}{\multicolumn{5}{|c|}{$\begin{array}{l}\text { Interval Between } \\
\text { Valvotomy and Embolism }\end{array}$}} & \multicolumn{3}{|c|}{ Embolic Episodes } \\
\hline & & & & & \multirow{2}{*}{$\begin{array}{c}\begin{array}{c}\text { Sinus } \\
\text { Rhythm }\end{array} \\
4 \\
7 \\
1 \\
\end{array}$} & \multirow{2}{*}{$\begin{array}{c}\begin{array}{c}\text { Atrial } \\
\text { Fibrillation }\end{array} \\
6 \\
5 \\
4\end{array}$} & \multirow{2}{*}{$\begin{array}{r}\text { Total } \\
10 \\
12 \\
5 \\
\end{array}$} \\
\hline $\begin{array}{c}<1 \text { year } \\
1-5 \text { years } \\
>5 \quad "\end{array}$ & $\ddot{x}$ & $\begin{array}{l}. \\
\cdots \\
.\end{array}$ & $\begin{array}{l}\cdots \\
\cdots \\
\end{array}$ & $\begin{array}{l}\cdots \\
\cdots\end{array}$ & & & \\
\hline Total & . & . & . & . & 12 & 15 & 27 \\
\hline
\end{tabular}

10 have now been followed up for a total of 65 patient-years. None of these 10 patients were on anticoagulant treatment.

\section{Anticoagulant Treatment}

Two groups of patients were treated with anticoagulants.

In 23 patients anticoagulant treatment was begun after the first or second embolic episode, and at the time of writing they had completed 58 treatment-years. In this group there were two embolic recurrences, but one occurred 16 days after anticoagulants had been temporarily discontinued because of surgical treatment of an ischio-rectal abscess. Anticoagulant treatment was immediately resumed, but, in spite of this and an attempt at embolectomy, the patient's leg could not be saved. Amputation was carried out later under anticoagulant prophylaxis. In the other patient the prothrombin level at the time of the embolus was within the recommended therapeutic range. She had a cerebral embolus causing dysarthria and hemiparesis, but made a full recovery within a few hours. This patient had a previous cerebral embolus 12 years before and underwent mitral valvotomy nine years before. Thus the incidence of recurrent embolism in the anticoagulant group was $3.4 \%$ per patient-year as compared with an incidence of 9.6\% per patient-year in 46 patients who survived the first embolic episode and were not put on anticoagulants (Table IV).

TABLE IV.-Embolic Recurrences With and Without Anticoagulant Prophylaxis

\begin{tabular}{|c|c|c|c|c|c|c|c|}
\hline \multirow[b]{2}{*}{ Cardiac Rhythm } & & \multicolumn{3}{|c|}{ Anticoagulant Treatment } & \multicolumn{3}{|c|}{$\begin{array}{l}\text { No Anticoagulant } \\
\text { Treatment }\end{array}$} \\
\hline & & No. & No. of & No. of & & $\begin{array}{l}\text { Period } \\
\text { of }\end{array}$ & No. of \\
\hline $\begin{array}{l}\text { Sinus } \\
\text { Atrial fibrillation }\end{array}$ & $\ddot{x}$ & $\begin{array}{r}8 \\
15\end{array}$ & $\begin{array}{l}20 \\
38\end{array}$ & $\begin{array}{l}0 \\
2 *\end{array}$ & $\begin{array}{l}14 \\
32\end{array}$ & $\begin{array}{r}46 \\
110\end{array}$ & $\begin{array}{l}7 \\
8\end{array}$ \\
\hline Total & . & 23 & 58 & $2 *$ & 46 & 156 & 15 \\
\hline
\end{tabular}

In another group of 30 patients with established atrial fibrillation and no history of embolism anticoagulants were started immediately or very shortly after the onset of atrial fibrillation and then continued for a total period of 46 patientyears. In this group two embolic episodes occurred during anticoagulant treatment. In one patient who had a mitral valvotomy five years previously the prothrombin level was considerably outside the accepted therapeutic range at the time of the embolus. She had a cerebral embolus causing facial weakness and hemiplegia but recovered fully within less than 24 hours. In the second patient who had a cerebral embolus the prothrombin level was within the accepted therapeutic range. She also made a full recovery within three hours. In a more or less comparable group of 98 patients from our rheumatic material who have been regularly seen in sinus rhythm and then in atrial fibrillation, but were not placed on anticoagulant treatment after the onset of atrial fibrillation, 29 patients had 34 embolic episodes in atrial fibrillation during a total period of 499 patient-years.

\section{Immediate Outcome and Subsequent Course}

Of the 63 episodes of cerebral embolism, 4 initial attacks and 4 recurrences were fatal, 17 embolic episodes were followed by partial recovery, and the remaining 38 by full recovery. One mesenteric embolus resulted in death. Two peripheral embolic episodes resulted in the loss of a limb. During the follow-up period 14 patients died from causes unrelated to embolism beween one day and nine years after the initial embolic episode (average survival period, 2.8 years). 


\section{Discussion}

In a group of 754 cases of chronic rheumatic heart disease $9.6 \%$ of the patients had systemic emboli. The overall incidence of embolism was $1.5 \%$ per patient-year. This is a low figure, but the material includes a large number of patients followed up for many years virtually in a stage of nonvulnerability. Rowe et al. (1960) reported only a slightly higher incidence of embolism, just under $2 \%$ per patientyear, in 250 patients followed for 10 years. A much higher incidence was observed by other authors (Olesen, 1955; Bannister, 1960 ; Greenwood et al., 1963), but it seems that these authors analysed a more selected group of patients.

Systemic embolism is more common in atrial fibrillation than in sinus rhythm. Harris and Levine (1941) and Greenwood et al. (1963) reported that $75 \%$ and $83 \%$ of their patients respectively had atrial fibrillation at the time of the embolic episodes. In our own material $64 \%$ of the emboli occurred in atrial fibrillation, giving an incidence of $5 \%$ per patientyear as compared with an incidence of $0.7 \%$ per patient-year in sinus rhythm. Emboli tend to occur shortly after the onset of atrial fibrillation (Belcher and Somerville, 1955 ; Riss and Levine, 1958). In Belcher and Somerville's series the duration of atrial fibrillation was known in 24 patients ; nearly one-third of these developed emboli within six months and two-thirds within three years of the onset of atrial fibrillation. In those of our own patients in whom the duration of atrial fibrillation was known, one-third of the emboli occurred within one month and about two-thirds within one year of the onset of atrial fibrillation.

While the probability of a patient developing an initial systemic embolus cannot be determined exactly as emphasized by Ellis and Harken (1961), there is good evidence to show that the chance of recurrence is far greater than that of a first episode (Askey, 1957). Daley et al. (1951) found recurrences in $60 \%$ of the patients, and the majority of the recurrences occurred within six months of each other. Belcher and Somerville (1955) reported that $35 \%$ of their patients suffered two or more embolic episodes. In the series of Rowe et al. (1960) nearly one-half of the patients who survived the first embolic episode had a second episode, half of these occurring within a year after the first embolus. In our present series, $19.5 \%$ of the patients had more than one embolus. The recurrence rate was $8 \%$ per patient-year, but $40 \%$ of the recurrences took place within one month and $66 \%$ within 12 months of the initial episode. It is noteworthy that recurrences occurred just as often in sinus rhythm as in atrial fibrillation.

Opinion is not unanimous regarding the protective value of mitral valvotomy against systemic embolism. Ellis and Harken (1961) concluded that the incidence of post-operative embolism was greatly reduced and expressed the opinion that there was a strong indication for mitral valvotomy in all patients who have had an arterial embolus, even without significant symptoms of cardiac disability. A similar reduction in the incidence of post-operative embolism was reported by Ricordeau et al. (1957) and Estes (1961). Belcher and Somerville (1955) concluded that a successful valvotomy will not prevent further systemic embolism, but there was reason to believe that it will reduce its incidence. Greenwood et al. (1963) were of the opinion that mitral valvotomy reduced both the occurrence and the recurrence of systemic emboli. They even concluded that valvotomy provided a better protection against embolic recurrences than anticoagulant treatment. Lowther and Turner (1962) followed 185 patients for six years after mitral valvotomy and found an incidence of embolism of $1.4 \%$ per patient-year. They felt that this was lower than might have been expected if operation had not been carried out. On the other hand, several authors found a sufficiently high incidence of embolism after mitral valvotomy to doubt its protective effect (Wang et al., 1960 ; Taber and Lam, 1960 ; Kellogg et al., 1961). Our own data have also failed to confirm the protective value of mitral valvotomy. It is noteworthy that 19 of our patients had their initial systemic embolus after mitral valvotomy.

Wright and Foley (1947) and Wright (1949) drew attention to the favourable effect of continuous anticoagulant therapy on the incidence of embolic recurrences in rheumatic heart disease. Cosgriff (1950) stated that although it was obviously impossible to establish the fact that the incidence of embolic recurrences was significantly reduced by anticoagulant therapy, the clinical course of their patients during anticoagulant therapy and the comparison with their previous course strongly suggested that a favourable effect was produced. The more recent studies of Wood and Conn (1954) and of Askey (1957) also suggest that long-term anticoagulant therapy is an effective means of preventing embolic recurrences. Owren (1963) studied 15 patients who were treated with anticoagulants after the first embolic episode. They have been on anticoagulant prophylaxis for a total period of 90 years and only one embolic episode has occurred. The control group of 17 patients experienced 22 embolic episodes in 81 observation-years. He believes that all patients with mitral-valve disease who have experienced embolism should be placed on lifelong anticoagulant prophylaxis. He has also selected patients for prophylaxis without a history of embolism, based on a calculated high risk of embolism as evaluated from the clinical condition, the stage of the disease, the age of the patient, and the presence of atrial fibrillation or a large left atrium. Douglas (1962) expressed the opinion that rheumatic heart disease with emboli was one of the major therapeutic indications for long-term anticoagulant therapy. Askey and Bernstein (1960) suggested that even a moderate reduction of the prothrombin level to $30-50 \%$ of normal greatly reduced the danger of arterial embolism without undue risk of haemorrhage.

In our limited experience anticoagulants seem to have had a protective effect against embolic recurrences. We have found that recurrences were at least two and a half times more frequent in those not treated with anticoagulants than in those on anticoagulant therapy. When patients with atrial fibrillation but without a history of embolism were put on anticoagulants the difference in the incidence of embolism in the treated and non-treated groups, as calculated on a percentage basis per patient-year, was less significant. However, if one takes the absolute figures the difference is striking : out of 30 patients on anticoagulants 2 had two embolic episodes, and out of 98 patients not on anticoagulants 29 had 34 embolic episodes. The apparent discrepancy between the absolute figures and those calculated on a percentage basis per patient-year is due mainly to the fact that the average followup period in the so-called control group was significantly longer than in the treated group. Experience shows that a significant number of all emboli occur comparatively early after the onset of atrial fibrillation. With the passage of time the risk of initial embolism and of recurrences becomes less. This is also the view of Greenwood et al. (1963).

It seems that in the natural course of rheumatic heart disease the first year after the onset of atrial fibrillation, and again the first year after the initial embolic episode, irrespective of the nature of the cardiac rhythm, represent the periods of greatest vulnerability. The onset of atrial fibrillation in the presence of rheumatic heart disease should be regarded as a medical emergency, as emphasized by Wood (1956). In addition to the generally accepted therapeutic measures at this turning-point, conversion to sinus rhythm with anticoagulant prophylaxis should be attempted even in the absence of a history of embolism. Should the attempt at restoring sinus rhythm fail, continuous anticoagulant therapy should be considered at least for a year, but probably for a 
much longer period in selected cases. Long-term anticoagulant therapy should also be considered in patients after the first embolic episode, both in sinus rhythm and in atrial fibrillation. This is our present practice.

We intend to continue and to extend this study in the hope that it will enable us to define the place of anticoagulant treatment in the prevention of systemic embolism in rheumatic heart disease in a more satisfactory manner. It is, of course, fully appreciated that this aim can be achieved only if the study includes a proper control group. At the same time it should be emphasized that a more rational long-term approach to this problem is the prevention of the development of a vulnerable stage of the underlying rheumatic disease. Antistreptococcal prophylaxis should be introduced very early in the course of rheumatic cardiac involvement, and certainly before the valvular lesion has reached a degree severe enough to lead to significant haemodynamic alterations and to progressive cardiac changes irrespective of future rheumatic activity.

\section{Summary}

The risk of systemic embolism is assessed in a group of 754 patients with chronic rheumatic heart disease followed over a period of 5,833 patient-years.

The incidence of embolism was $1.5 \%$ per patient-year for the whole group. It was seven times higher in atrial fibrillation than in sinus rhythm. When the duration of atrial fibrillation was known, it was found that one-third of the emboli occurred within one month and two-thirds within 12 months after the onset of atrial fibrillation. The incidence of embolic recurrences was $8 \%$ per patient-year, irrespective of the nature of the cardiac rhythm, but $66 \%$ of the recurrences took place within 12 months of the initial embolic episode.

Mitral valvotomy did not eliminate the danger of embolism. It is questionable whether it reduced its incidence.

Anticoagulant treatment reduced the incidence of embolic recurrences.

\section{REFERENCES}

Askey, J. M. (1957). Systemic Arterial Embolism, pp. 28, 102. Grune and Stratton, New York.

- and Bernstein, S. (1960). Progr. cardiovasc. Dis., 3, 220.

Bannister, R. G. (1960). Lancet, 2, 329.

Belcher, J. R., and Somerville, W. (1955). Brit. med. f., 2, 1000.

Cosgriff, S. W. (1950). F. Amer. med. Ass., 143, 870.

Daley, R., Mattingly, T. W., Holt, C. L., Bland, E. F., and White, P. D. (1951). Amer. Heart 7., 42, 566.

Douglas, A. S. (1962). Anticoagulant Therapy, p. 220. Blackwell, Oxford.

Ellis, L. B., and Harken, D. E. (1961). Amer. Heart f., 62, 611.

Estes, D. (1961). Amer. F. Med., 30, 449.

Greenwood, W. F., Aldridge, H. E., and McKelvey, A. D. (1963). Amer. F. Cardiol., 11, 348.

Harris, A. W., and Levine, S. A. (1941). Ann. intern. Med., 15, 637.

Kellogg, F., Chi Kong Liu, Fishman, I. W., and Larson, R. (1961). Circulation, 24, 263.

Lowther, C. P., and Turner, R. W. D. (1962). Brit. med. F., 1, 1027.

Olesen, K. H. (1955). Mitral Stenosis, p. 139. Munksgaard, Copenhagen.

Owren, P. A. (1963). Arch. intern. Med., 111, 240.

Ricordeau, G., Coblentz, B., and Lenègre, J. (1957). Arch. Mal. Cour, 50, 112.

Riss, E., and Levine, S. A. (1958). Amer. Heart f., 56, 831.

Rowe, J. C., Bland, E. F., Sprague, H. B., and White, P. D. (1960). Ann. intern. Med., 52, 741 .

Taber, R. E., and Lam, C. R. (1960). Circulation, 22, 821.

Wang, Y., Bland, E. F., and Scannell, J. G. (1960). Ibid., 22, 829.

Wood, J.'C., and Conn, H. L. (1954). Ibid., 10, 517.

Wood, P. (1954). Brit. med. f., 1, 1051 . 552. Eyre and Spottiswoode, London.

Wright, I. S. (1949). Ann. intern. Med., 30, 80

and Foley, W. T. (1947). Amer. F. Med., 3, 718.
The lymphoma syndrome first described by Burkitt in 1958 is found over large areas of tropical Africa. The age of maximum incidence of the disease is 5-6 years, and from the evidence of his safaris Burkitt (1962) has concluded that the data are not inconsistent with a postulated arbovirus aetiology. The suggestion of a virus aetiology first came from J. N. P. Davies (see Burkitt, 1962).

Previous attempts to isolate viruses from the lymphoma in vitro gave Herpes hominis from 6 out of 50 biopsies (Woodall and Haddow, 1962 ; Simons and Ross, 1963), and a virus which might well be of the herpes group has been seen by Epstein et al. (1964) in cultured cells from a Burkitt tumour. Dalldorf and Bergamini (1964) recovered six strains of virus from lymphomas in Kenya. These were compared with ethersensitive viruses and tested against the adenovirus group antigen.

This preliminary study reports the isolation of a reovirus, probably related antigenically to type 3, from Maitland-type cultures of a Burkitt tumour biopsy. This would also appear to be the first recovery of a reovirus in East Africa.

\footnotetext{
* Imperial Cancer Research Fund, East African Virus Research Institute, P.O. Box 49, Entebbe, Uganda. † East African Virus Research Institute.
}

\section{Materials and Methods}

Media A, C, and E were prepared as described by Bell (1962). Calf serum and Eagle's MEM (Eagle, 1959) were supplied by Microbiological Associates Inc. Medium F was prepared by adding $10 \%$ calf serum to the MEM.

Human embryo kidney (H.E.K.), hamster kidney (Ham.K.), vervet monkey kidney (M.K.), and human amnion (H.A.) cell cultures were prepared by standard techniques (Bell et al., 1960 ; Bell, 1962), and trypsinized human embryo lung fibroblasts (H.E.Lu.) by the method of Hayflick and Moorhead (1961).

Tumour biopsies were collected from four cases of lymphoma at Mulago Hospital, Kampala, and kept in medium $\mathrm{A}$ at room temperature until treated. Maitland-type cultures (Maitland and Maitland, 1928) were prepared in medium $C$ in stationary tubes or plastic Petri dishes (Gateway International) and incubated at $37^{\circ} \mathrm{C}$.

Aliquots of $0.2 \mathrm{ml}$. of the suspensions of cells which grew from these biopsies were inoculated into roller-tube cultures of H.A., Ham.K., M.K., and H.E.Lu., and of $0.5 \mathrm{ml}$. into Petri-dish cultures of M.K. cells. Medium A was used for the maintenance of tube cultures and medium $F$ for plate cultures. 